\title{
Mental health problems and influencing factors in Japanese women 4 months after delivery
}

\author{
Naoko Yamamoto ${ }^{1}$, Yasuyo Abe ${ }^{1 *}$, Kazuhiko Arima', Takayuki Nishimura', Emi Akahoshi', Kazuyo Oishi ${ }^{2}$ \\ and Kiyoshi Aoyagi ${ }^{1}$
}

\begin{abstract}
Background: Postpartum mental health problems are a major public health issue; however, studies on the mental health status of mothers and its influencing factors between 8 weeks and 1 year postpartum are scarce.

Furthermore, it would be necessary to examine the factors influencing mothers' mental health in order to evaluate their physiological adaptations to the nursing environment.

Methods: We examined the mental health status of postpartum women and the factors influencing poor mental health at 4 months after delivery. A cross-sectional study of 584 postpartum women was conducted. Information on mental health status, delivery, and other factors was collected using a self-administered questionnaire. Women were asked about their age, height, weight, gestational or marital status, whether they were eating regular meals, appetite, frequency of going out, financial difficulty, stressful life events, and history of depression. The Japanese version of the 12-item General Health Questionnaire (GHQ-12) was used to identify potential poor mental health status. Participants with GHQ-12 scores of $\geq 4$ were classified as the high GHQ-12 score group (poor mental health status) and participants with GHQ-12 scores of $\leq 3$ were classified as the low GHQ-12 score group (good mental health status).
\end{abstract}

Results: Forty-five women (7.7\%) were classified as having high GHQ-12 scores. Multiple logistic regression analysis revealed that older age, not eating meals regularly, and history of depression were significantly associated with poor mental health. Financial difficulty had a borderline association with poor mental health in this model.

Conclusions: These risk factors might help practitioners identify women at high risk of poor mental health after delivery.

Keywords: Depression, Financial difficulty, GHQ-12, Mental health, Postpartum, Regular eating

\section{Background}

Postpartum mental health problems are a major public health issue [1]. The most common of these problems is postpartum depression, which usually occurs 4 to 6 weeks after childbirth [2] but can occur up to 1 year postpartum [3]. The prevalence of postpartum depression has been reported to be 10 to $14 \%$ [4-7]. Postpartum depression can have adverse effects not only on affected mothers, but also on their children's development and on the well-being of the whole family [8-10].

The 12-item General Health Questionnaire (GHQ-12) is a valid, internationally used measure of mental health

\footnotetext{
* Correspondence: yasuyo-a@nagasaki-u.ac.jp

${ }^{1}$ Department of Public Health, Nagasaki University Graduate School of Biomedical Sciences, 1-12-4, Sakamoto, Nagasaki 852-8523, Japan Full list of author information is available at the end of the article
}

status in a population. High GHQ-12 scores have frequently been used to identify the possible presence of psychological disorders. Several studies used the GHQ-12 in order to assess postpartum mothers' mental health status [11-13].

Some of the reported risk factors of postpartum depression are low social status, stressful life events, psychological disturbance during pregnancy, a poor marital relationship, low social support, and past history of psychopathology $[7,14,15]$. Studies on the mental health status of mothers have mostly been conducted 4 to 8 weeks $[12,16,17]$ or 1 year $[11,18,19]$ after delivery. However, it is critical to gain better insight into mothers' mental health between 8 weeks and 1 year postpartum to fully understand postpartum mental health problems. Furthermore, it would be necessary to examine the factors 
influencing mothers' mental health in order to evaluate their physiological adaptations to the nursing environment. Therefore, the purpose of this study was to assess the mental health condition of mothers 4 months after delivery and to elucidate the factors influencing poor mental health.

\section{Participants and methods}

A cross-sectional study was conducted in two healthcare centers in Nagasaki, Japan, from November 2011 to July 2012. A total of 646 women whose infants underwent a 4-month health examination at these centers were invited to participate in this study, and 602 women gave written informed consent to participate (participation rate: 93.2\%). This study was approved by the Ethical Committee of Nagasaki University, Graduate School of Biomedical Sciences (approval number 11090863).

\section{Questionnaire}

Information on mental health status, delivery, and other factors was collected using a self-administered questionnaire. Women were asked about their age, height, weight, gestational age at delivery, parity (primiparous/multiparous), method of delivery (vaginal/caesarean section), gestational stage at delivery (preterm, full term, or post term), marital status (married or living with a partner, single, divorced, or widowed), whether the pregnancy was planned (yes/no), method of infant feeding (breastfeeding, partially breastfeeding, or formula feeding), whether they were eating meals regularly (yes/no), appetite (good/poor), frequency of going out (almost every day, 2 to 3 times a week, once a week, 1 to 2 times a month, or less than once a month), financial difficulty (yes/no), stressful life events (yes/no), and history of depression (yes/no).

The Japanese version of the GHQ-12 was used to identify potential poor mental health status. High GHQ-12 scores have frequently been used to identify the possible presence of psychological disorders. The 12 items assessed by the GHQ-12 are lost sleep, feelings of being under strain, inability to concentrate, feeling unable to play a useful role, inability to face problems, inability to make decisions, inability to overcome difficulties, feeling unhappy, lack of enjoyment in day-to-day activities, feeling depressed, lack of confidence, and feelings of worthlessness. Responses were given on a 4-point scale (corresponding to the presence of symptoms: "not at all," "same as usual," "slightly more than usual," or "much more than usual"), and were scored in a bimodal fashion (0-0-1-1). Total scores ranged from 0 to 12 , with higher scores indicating that the respondent experienced more symptoms of psychological distress. Participants with GHQ-12 scores of $\geq 4$ were classified as the high GHQ-12 score group and participants with GHQ-12 scores of $\leq 3$ were classified as the low GHQ-12 score group.

\section{Statistical analysis}

Participants with any missing questionnaire responses were excluded, leaving 584 women for the final analysis. The $x^{2}$ test, Fisher exact test, and Student's $t$-test were used to assess differences between the high and low GHQ-12 score groups. Multiple logistic regression analysis was used to evaluate the simultaneous effects of variables on high GHQ-12 scores. Odds ratios and 95\% confidence intervals were calculated. Starting with a full model including all variables, the most appropriate model was selected based on Akaike's information criteria. $P$ values $<0.05$ were considered significant. Statistical analysis was performed using SPSS software version 19 for Windows (SPSS Japan, Tokyo, Japan).

\section{Results}

Table 1 shows the characteristics of the participants. The mean (standard deviation) age of participants was 31.4 (5.1) years old. The majority (86.8\%) of the women ate meals regularly, $20 \%$ reported financial difficulty, and $6.2 \%$ reported a history of depression.

Table 2 shows the univariate comparison of variables between the high and low GHQ-12 score groups. Fortyfive women $(7.7 \%)$ were classified as having high GHQ12 scores (poor mental health status), and their mean age was significantly older compared to women with low GHQ-12 scores (good mental health status). Women with high GHQ-12 scores showed significantly higher prevalence of not eating meals regularly, poor appetite, financial difficulty, and history of depression compared to women with low GHQ-12 scores.

Multiple logistic regression analysis revealed that older age, not eating meals regularly, and history of depression were significantly associated with high GHQ-12 score (Table 3). Financial difficulty had a borderline association with high GHQ-12 scores in this model. We added the analysis in women without history of depression. Older age and not eating meals regularly were significantly associated (data not shown).

\section{Discussion}

In the present study, $7.7 \%$ of mothers had poor mental health (high GHQ-12 score) at 4 months postpartum, with the factors associated with poor mental health status being older age, not eating meals regularly, history of depression, and financial difficulty.

The prevalence of poor mental health (GHQ-12 score of 24) among women 4 months after delivery observed in this study was lower than previous reports on postpartum mothers $[12,13]$. In Italy, the prevalence of poor mental health among women 6 to 8 weeks after delivery was 13\% [12]. Furthermore, a study in the United Kingdom reported that $23.5 \%$ of women 3 to 6 months after delivery had a GHQ-12 score of $\geq 4$ [13]. These differences may be 
Table 1 Participant characteristics

\begin{tabular}{|c|c|c|}
\hline \multirow{2}{*}{ Variable } & \multicolumn{2}{|c|}{$(n=584)$} \\
\hline & Average & SD \\
\hline Age (years) & 31.4 & 5.1 \\
\hline Height (cm) & 158.1 & 5.3 \\
\hline Weight (kg) & 51.9 & 7.0 \\
\hline \multirow[t]{2}{*}{ Gestational age at delivery (weeks) } & 38.9 & 1.5 \\
\hline & $\mathbf{n}$ & $\%$ \\
\hline \multicolumn{3}{|l|}{ Parity } \\
\hline Primiparous & 279 & 47.8 \\
\hline Multiparous & 305 & 52.2 \\
\hline \multicolumn{3}{|l|}{ Methods of birth } \\
\hline Vaginal birth & 507 & 86.8 \\
\hline Caesarean section & 77 & 13.2 \\
\hline \multicolumn{3}{|l|}{ Term } \\
\hline Preterm (<37 weeks) & 30 & 5.1 \\
\hline Full term (37-41 weeks) & 547 & 93.7 \\
\hline Post term ( $\geq 42$ weeks) & 7 & 1.2 \\
\hline \multicolumn{3}{|l|}{ Marital status } \\
\hline Married or living with partner & 567 & 97.1 \\
\hline Single & 13 & 2.2 \\
\hline Divorced & 4 & 0.7 \\
\hline Widowed & 0 & 0 \\
\hline \multicolumn{3}{|l|}{ Pregnancy } \\
\hline Planed & 440 & 75.3 \\
\hline Not planed & 144 & 24.7 \\
\hline \multicolumn{3}{|l|}{ Breastfeeding status } \\
\hline Fully breastfeeding & 383 & 65.6 \\
\hline Partially breastfeeding & 143 & 24.5 \\
\hline Formula feeding & 58 & 9.9 \\
\hline \multicolumn{3}{|l|}{ Eating meals regularly } \\
\hline Yes & 507 & 86.8 \\
\hline No & 77 & 13.2 \\
\hline \multicolumn{3}{|l|}{ Appetite } \\
\hline Good & 559 & 95.7 \\
\hline Poor & 25 & 4.3 \\
\hline \multicolumn{3}{|l|}{ Frequency of going out } \\
\hline Almost everyday & 255 & 43.7 \\
\hline 2-3 times a week & 251 & 43.0 \\
\hline Once a week & 61 & 10.4 \\
\hline $1-2$ times a month & 13 & 2.2 \\
\hline Less & 4 & 0.7 \\
\hline \multicolumn{3}{|l|}{ Financial difficulty } \\
\hline No & 467 & 80.0 \\
\hline Yes & 117 & 20.0 \\
\hline
\end{tabular}

Table 1 Participant characteristics (Continued)

\begin{tabular}{lcc}
\hline Stressful life events experienced & & \\
Yes & 183 & 31.3 \\
No & 401 & 68.7 \\
History of depression & & \\
Yes & 36 & 6.2 \\
No & 548 & 93.8 \\
\hline
\end{tabular}

due to the cultural background and environment specific to each country. A study comparing the rates of psychological distress of women 1 year after childbirth in France, Italy, and Canada showed that differences between the rates in these countries were present, and that although the reason for the differences was unclear, distress may be expressed differently between countries [11]; therefore, careful attention is needed when interpreting results from different countries.

Nakao et al. [20] recently assessed the mental health status of the general population in Nagasaki, and reported that the prevalence of poor mental health (GHQ-12 score of $\geq 4$ ) was $34.4 \%$ in women aged 20 to 39 years, and was $17.9 \%$ in women aged 40 to 64 years, which were both higher than the prevalence observed in our study. To date, there is no clear evidence of whether mental health problems are more or less common among postpartum women than non-postpartum women. One study reported higher prevalence of depressive disorder among postpartum women than a control group [21], another reported lower prevalence of depressive disorder among postpartum women than non-postpartum women [22], and others reported no significant difference between postpartum women and controls $[13,23]$. Further studies are necessary to clarify this issue; however, considering the significant negative impact on mothers and children [8-10], postpartum mental health problems are definitely one of the most important global public health issues.

In the present study, older age was significantly associated with poor mental health as assessed by the GHQ12 among postpartum women. However, some studies reported that younger maternal age was associated with postpartum mental health problems [24,25]. On the other hand, Bjerke et al. [26] reported that among Pakistani women, the probability of postpartum depression at 6 to 12 weeks after delivery was 4.6 times higher in women over 30 years of age compared to women under 30. Other studies have reported no significant difference in mean age between postpartum women with and without poor mental health [16,27]. As mentioned above, these differences may be due to the specific cultural and social background of each country. Further studies are needed to clarify this association. 
Table 2 Comparison of the high (poor mental health status) and low (good mental health status) GHQ-12 score groups

\begin{tabular}{|c|c|c|c|c|c|c|}
\hline \multirow[t]{2}{*}{ Variable } & & $\begin{array}{l}\text { High GHQ-12 score } \\
\qquad(n=45)\end{array}$ & & $\begin{array}{l}\text { Low GHQ-12 score } \\
\qquad(n=539)\end{array}$ & & $\begin{array}{c}(\mathrm{n}=584) \\
P \text { value }\end{array}$ \\
\hline & & Average & SD & Average & SD & \\
\hline Age (years) & & 33.6 & 5.5 & 31.2 & 5.1 & $<0.01$ \\
\hline Height (cm) & & 158.3 & 5.1 & 158.1 & 5.3 & 0.80 \\
\hline Weight (kg) & & 51.7 & 7.3 & 51.9 & 6.9 & 0.86 \\
\hline \multirow[t]{2}{*}{ Gestational age at delivery (weeks) } & & 39.0 & 1.6 & 38.9 & 1.5 & 0.86 \\
\hline & & $N$ & $\%$ & N & $\%$ & \\
\hline Parity & Primiparous & 22 & 48.9 & 257 & 47.7 & 0.50 \\
\hline Method of birth & Caesarean section & 4 & 8.9 & 73 & 13.5 & 0.49 \\
\hline Term & Preterm & 4 & 8.9 & 26 & 4.8 & 0.28 \\
\hline Marital status & Single or Divorced & 3 & 6.3 & 14 & 2.6 & 1.00 \\
\hline Pregnancy & Not planned & 16 & 35.6 & 128 & 23.7 & 0.10 \\
\hline Breastfeeding status & Partially breastfeeding or Formula feeding & 21 & 46.7 & 180 & 33.4 & 0.08 \\
\hline Eating meals regularly & No & 12 & 26.7 & 65 & 12.1 & 0.01 \\
\hline Appetite & Poor & 5 & 11.1 & 20 & 3.7 & 0.04 \\
\hline Frequency of going out & No or $1-2$ times a month & 1 & 5.9 & 16 & 94.1 & 1.00 \\
\hline Financial difficulty & Yes & 16 & 35.6 & 101 & 18.7 & 0.01 \\
\hline Stressful life events experienced & Yes & 14 & 31.1 & 169 & 31.4 & 1.00 \\
\hline History of depression & Yes & 11 & 24.4 & 25 & 4.6 & 0.01 \\
\hline
\end{tabular}

Financial difficulty or financial stress have been associated with depressive symptoms and mental health problems $[28,29]$. A study on mental health at the population level in Finland showed that a poor economic situation was associated with poor mental health status as assessed by the GHQ-12 [30]. Furthermore, some studies have pointed out that financial difficulties are a significant risk factor for postpartum mental health problems [18,24,31]. Romito et al. [18] reported that financial worries were associated with poor mental health status in Italian and French women 12 months after birth. Ngoma et al. [24] also reported a significant association between financial difficulty and mental health problems among Japanese women 1 month postpartum and speculated that this association might be partly attributed to increased levels of stress among mothers who lack the financial means necessary to raise their infants. In our study, financial difficulty

Table 3 Logistic regression analysis of factors associated with high GHQ-12 score

\begin{tabular}{lcccc}
\hline \multicolumn{1}{c}{ Variable } & Comparison & $\begin{array}{c}\text { Odds } \\
\text { ratio }\end{array}$ & $\mathbf{9 5 \%} \mathbf{C l}$ & $\boldsymbol{P}$ value \\
\hline Age & One year increase & 1.1 & $1.1-1.2$ & $<0.01$ \\
Eating meals regularly & No/Yes & 3.0 & $1.4-6.5$ & 0.01 \\
Financial difficulty & Yes/No & 2.0 & $1.0-4.0$ & 0.06 \\
History of depression & Yes/No & 6.0 & $2.6-14.0$ & $<0.01$ \\
\hline
\end{tabular}

had a borderline association with poor mental health, which is consistent with previous findings. New mothers with financial difficulty might represent a group that should be targeted to prevent poor mental health.

We showed that history of depression was significantly associated with poor mental health among Japanese mothers 4 months postpartum. Panthangi et al. [32] used the Edinburgh Postpartum Depression Scale to assess postpartum depression in women who had given birth during the previous 5 to 8 weeks and showed the relationship between postpartum depression and history of depression. Saleh et al. [27] also reported that prior psychiatric problems were a significant predictor of postpartum depression as assessed by the Edinburgh Postpartum Depression Scale. Our study together with previous reports suggests that, for women with prior history of depression, appropriate screening and early intervention may be needed to prevent postpartum mental health problems.

A previous study showed that not eating meals regularly was associated with poor mental health status among community-dwelling Japanese women [20]. This finding was consistent with our results. To the best of our knowledge, there have been no previous studies on the relationship between the regularity of eating meals and mental health status among postpartum women. Eating patterns might vary considerably among different 
cultures and countries, which makes it somewhat difficult to evaluate on an international scale. However, irregular eating patterns may lead to mental health problems, and vice versa. Further study is required to fully understand this association among postpartum women.

Several limitations of the present study should be considered. Firstly, because this was a cross-sectional design, our results do not necessarily show a causal relationship. Longitudinal studies are required to establish relationships between poor mental health and the associated factors. Secondly, the present study included only Japanese women; therefore, it is not possible to extrapolate the results to women of other ethnicities. Thirdly, it was reported that depression patients have abnormalities in baseline cortisol secretion [33]. It is necessary to obtain data on cortisol levels in future research.

The prevalence of poor mental health was relatively low in women at 4 months postpartum in this study. Older age, not eating meals regularly, and a history of depression were associated with poor mental health. Financial difficulty had a borderline association with poor mental health. The risk factors identified in the present study might help practitioners identify women at high risk of developing poor mental health after delivery and aid in early intervention to prevent postpartum depression.

\section{Abbreviations}

GHQ-12: 12-item General Health Questionnaire.

\section{Competing interests}

The authors declare that they have no competing interests.

\section{Authors' contributions}

NY carried out the design of the present study and data analysis, and drafted the manuscript. YA, KA, TN, and KA contributed to the design of the experiments and checked the manuscript. $\mathrm{AE}$ and $\mathrm{KO}$ contributed to data collection and analysis. All authors read and approved the final manuscript.

\section{Acknowledgements}

This study was supported in part by JSPS KAKENHI (25650157).

\section{Author details}

${ }^{1}$ Department of Public Health, Nagasaki University Graduate School of Biomedical Sciences, 1-12-4, Sakamoto, Nagasaki 852-8523, Japan. ${ }^{2}$ Department of Reproductive Health, Unit of Nursing, Nagasaki University Graduate School of Biomedical Sciences, 1-7-1, Sakamoto, Nagasaki 852-8102, Japan.

Received: 19 August 2014 Accepted: 12 October 2014

Published: 29 October 2014

\section{References}

1. Ross-Davie M, Elliott S, Sarkar A, Green L: A public health role in perinatal mental health: are midwives ready? Br J Midwifery 2006, 14:330-334

2. Glavin K, Leahy-Warren P: Postnatal depression is a public health nursing issue: perspectives from Norway and Ireland. Nurs Res Pract 2013, 2013:813409.

3. Gavin NI, Gaynes BN, Lohr KN, Meltzer-Brody S, Gartlehner G, Swinson T: Perinatal depression: a systematic review of prevalence and incidence. Obstet Gynecol 2005, 106:1071-1083.

4. Buist AE, Barnett BE, Milgrom J, Pope S, Condon JT, Ellwood DA, Boyce PM, Austin M-PV, Hayes BA: To screen or not to screen-that is the question in perinatal depression. Med J Aust 2002, 177:S101.
5. Gale S, Harlow B: Postpartum mood disorders: a review of clinical and epidemiological factors. Psychosom Obstet Gynecol 2003, 24:257-266.

6. Leahy-Warren P, McCarthy G, Corcoran P: Postnatal depression in first-time mothers: prevalence and relationships between functional and structural social support at 6 and 12 weeks postpartum. Arch Psychiatr Nurs 2011, 25:174-184.

7. O'hara MW, Swain AM: Rates and risk of postpartum depression-a meta-analysis. Int Rev Psychiatr 1996, 8:37-54.

8. Areias ME, Kumar R, Barros H, Fiqueiredo E: Correlates of postnatal depression in mothers and fathers. Br J Psychiatry 1996, 169:36-41.

9. Boath E, Pryce A, Cox J: Postnatal depression: the impact on the family. J Reprod Infant Psychol 1998, 16:199-203.

10. Tammentie T, Tarkka MT, Astedt - Kurki P, Paavilainen E: Sociodemographic factors of families related to postnatal depressive symptoms of mothers. Int J Nurs Pract 2002, 8:240-246.

11. Des Rivieres-Pigeon C, Saurel-Cubizolles MJ, Romito P: Psychological distress one year after childbirth: a cross-cultural comparison between France, Italy and Quebec. Eur J Public Health 2003, 13:218-225.

12. Grussu P, Quatraro RM: Prevalence and risk factors for a high level of postnatal depression symptomatology in Italian women: a sample drawn from ante-natal classes. Eur Psychiatry 2009, 24:327-333.

13. Van Bussel JC, Spitz B, Demyttenaere K: Women's mental health before, during, and after pregnancy: a population - based controlled cohort study. Birth 2006, 33:297-302

14. Da Costa D, Dritsa M, Rippen N, Lowensteyn I, Khalife S: Health-related quality of life in postpartum depressed women. Arch Womens Ment Health 2006, 9:95-102.

15. Boyce P, Hickey A: Psychosocial risk factors to major depression after childbirth. Soc Psychiatry Psychiatr Epidemiol 2005, 40:605-612.

16. McConachie H, Hammal D, Welsh B, Keane B, Waterston T, Parker L, Cook M: Wellbeing of new mothers. Community Pract 2008, 81:19-22.

17. Aguado J, Campbell A, Ascaso C, Navarro P, Garcia-Esteve L, Luciano JV: Examining the factor structure and discriminant validity of the 12-item general health questionnaire (GHQ-12) among Spanish postpartum women. Assessment 2012, 19:517-525.

18. Romito P, Saurel-Cubizolles MJ, Lelong N: What makes new mothers unhappy: psychological distress one year after birth in Italy and France. Soc Sci Med 1999, 49:1651-1661.

19. Saurel-Cubizolles M-J, Romito P, Ancel P-Y, Lelong N: Unemployment and psychological distress one year after childbirth in France. J Epidemiol Community Health 2000, 54:185-191.

20. Nakao R, Honda S, Moji K, Abe Y, Aoyagi K: Relationship between lifestyle and mental health: a population-based survey in Nagasaki prefecture, Japan. Acta Med Nagasaki 2011, 55:55-60.

21. Augusto A, Kumar R, Calheiros J, Matos E, Figueiredo E: Post-natal depression in an urban area of Portugal: comparison of childbearing women and matched controls. Psychol Med 1996, 26:135-141.

22. Eberhard-Gran M, Eskild A, Tambs K, Samuelsen S, Opjordsmoen S: Depression in postpartum and non-postpartum women: prevalence and risk factors. Acta Psychiatr Scand 2002, 106:426-433.

23. Regmi S, Sligl W, Carter D, Grut W, Seear M: A controlled study of postpartum depression among Nepalese women: validation of the Edinburgh Postpartum Depression Scale in Kathmandu. Trop Med Int Health 2002, 7:378-382.

24. Ngoma AM, Goto A, Suzuki Y, Tsutomi H, Yasumura S: Support-seeking behavior among Japanese mothers at high-risk of mental health problems: a community-based study at a city health center. Fukushima J Med Sci 2012, 58:117-126.

25. Wolf AW, De Andraca I, Lozoff B: Maternal depression in three Latin American samples. Soc Psychiatry Psychiatr Epidemiol 2002, 37:169-176.

26. Bjerke SE, Vangen S, Nordhagen R, Ytterdahl T, Magnus P, Stray-Pedersen B: Postpartum depression among Pakistani women in Norway: prevalence and risk factors. J Matern Fetal Neonatal Med 2008, 21:889-894.

27. el Saleh S, El-Bahei W, Del El-Hadidy MA, Zayed A: Predictors of postpartum depression in a sample of Egyptian women. Neuropsychiatr Dis Treat 2013, 9:15-24

28. Coiro MJ: Depressive symptoms among women receiving welfare. Women Health 2001, 32:1-23.

29. Starkey AJ, Keane CR, Terry MA, Marx JH, Ricci EM: Financial distress and depressive symptoms among African American Women: identifying financial priorities and needs and why it matters for mental health. J Urban Health 2013, 90:83-100. 
30. Viinamäki H, Hintikka J, Kontula O, Niskanen L, Koskela K: Mental health at population level during an economic recession in Finland. Nord J Psychiatr 2000, 54:177-182.

31. Reading R, Reynolds S: Debt, social disadvantage and maternal depression. Soc Sci Med 2001, 53:441-453.

32. Panthangi V, West P, Savoy-Moore RT, Geeta M, Reickert E: Is seasonal variation another risk factor for postpartum depression? J Am Board Fam Med 2009, 22:492-497.

33. Young EA, Lopez JF, Murphy-Weinberg V, Watson SJ, Akil H: Hormonal evidence for altered responsiveness to social stress in major depression. Neuropsychopharmacology 2000, 23:411-418.

doi:10.1186/1880-6805-33-32

Cite this article as: Yamamoto et al: Mental health problems and influencing factors in Japanese women 4 months after delivery. Journal of Physiological Anthropology 2014 33:32.

\section{Submit your next manuscript to BioMed Central and take full advantage of:}

- Convenient online submission

- Thorough peer review

- No space constraints or color figure charges

- Immediate publication on acceptance

- Inclusion in PubMed, CAS, Scopus and Google Scholar

- Research which is freely available for redistribution 